\title{
1 Nasal Air-Conditioning During Breathing Therapy
}

2

3 David E. White ${ }^{1}$, Ahmed M. Al-Jumaily ${ }^{1}$, James Bartley ${ }^{2}$ and Andrew Somervell ${ }^{3}$

4

$5 \quad{ }^{1}$ Institute of Biomedical Technologies, Auckland University of Technology, Auckland, New Zealand.

$6 \quad$ 2Department of Surgery, University of Auckland, Auckland, New Zealand.

$7 \quad{ }^{3}$ Fisher and Paykel Healthcare, Auckland, New Zealand.

8

9

10 Running Title:

11 Nasal Air-Conditioning During Breathing Therapy

13 Corresponding Author:

14

15

Professor Ahmed Al-Jumaily

16 Institute of Biomedical Technologies,

17 Auckland University of Technology,

18 Private Bag 92006,

19 Auckland, 1142,

20 New Zealand.

21 E-mail: ahmed.aljumaily@aut.ac.nz

22 Tel: (+649) 9219777

23 Fax: (+649) 9219973 


\section{ABSTRACT}

2 It has been reported that continuous positive airway pressure therapy introduces negative nasal side3 effects including sneezing, itching, nasal dryness, nasal congestion and/or a runny nose. As these 4 symptoms are suggestive of nasal dysfunction, heated humidification is often used to fully saturate and 5 heat the inhaled air to core body temperature. It is expected that this relieves the nasal mucosa from 6 having to supply, or recover, heat and moisture from inspired and expired air. This review summarizes the 7 current in vitro and in vivo knowledge relevant to nasal air-conditioning, and identifies further 8 investigations necessary to improve our understanding the changes that occur during nasal continuous 9 positive airway pressure therapy. Investigations into nasal airway fluid transportation, airflow regulation and heat and fluid supply may lead to a therapy temperature/pressure/humidification algorithm that

11 optimizes these parameters for a prescribed therapy pressure. Optimization could lead to a reduction in titration pressure and improved treatment compliance.

\section{Keywords}

15 nasal air-conditioning, nasal mask, breathing therapy. 
1

2

3

\section{INTRODUCTION}

The nasal mask is a common interface through which air or other gas mixtures are delivered to a spontaneously breathing patient. Breathing dry gases through a nasal mask presents significant airconditioning challenges to the nose which may lead to desiccation of the nasal mucosa. Heated pass-over type humidifiers are commonly used to condition the gas to near full water saturation at core body temperature [1-3]. Other elevated pressure breathing therapy applications, such as nasal continuous positive airway pressure (n-CPAP) treatment for obstructive sleep apnea (OSA), utilize similar supplementary heating and humidification. Pressure related nasal complications have been reported by over $40 \%$ of n-CPAP users $[4,5]$. These include nasal crusting, dryness, congestion, sneezing, rhinorrhea and/or itching. The nose appears unable to adequately condition inhaled ambient air under slightly elevated pressures [2-4, 6-12]. Heated humidification is commonly utilized to treat these symptoms and improve patient comfort; however, its ability to improve treatment compliance is questionable $[5,7,13]$.

Currently no clear explanation exists as to why breathing ambient air at slightly elevated pressures induces these nasal symptoms. It has been suggested that these symptoms could have existed prior to initiation of therapy, however they commonly disappear with cessation of treatment [9]. Another suggestion attributes these symptoms to mouth leak [1, 14], where large unidirectional airflow occurs through the nose. This type of flow prevents expired air heat and moisture recovery from occurring within the airway fluid lining. These symptoms are also attributed to changes in nasal blood flow which occur due to the elevated pressures $[1,15]$. Further, age can contribute to negative nasal symptoms during breathing therapy. Functional changes occurring within the nose such as mucosal atrophy $[8,16]$, rather than nasal mask conditions, may also be responsible for these symptoms.

Within the airways, the ciliated respiratory epithelium is protected by a superficial gel layer of mucus, which is transported along the surface by the synchronized beating of the cilia within the periciliary liquid (PCL) or sol layer. These two fluid layers make up the airway surface liquid (ASL) lining the entire airway. Currently, heating and humidification requirements within most breathing therapy systems are pre-set in terms of both temperature and moisture content of the air delivered to the patient $[5,17]$. This conservative approach provides supplementary heated humidification that effectively relieves the nose of any air-conditioning role. Excessive supplementary water will cause dilution of the ASL, whilst 
insufficient water can lead to mucus thickening and drying [18]. Both of these conditions adversely affect mucociliary transport velocity (MTV), heat/moisture exchange and consequently ASL changes, which could lead to respiratory complications and thermal damage to airway tissue [19, 20].

This paper presents a comprehensive literature review to establish relationships between nasal applied breathing therapy and symptoms suggestive of airway mucosal dysfunction. This review starts with the nasal heat and moisture exchange, which is essential for any air-conditioning process, followed by nasal regulation systems. The latter have been reviewed in the context of their response to the physical properties of air pressure, flow, humidity and temperature. From a biomedical engineering perspectives, modeling is an essential part in understanding and predicting any physiological phenomena, modeling is reviewed followed by air-conditioning pathgophysiology. To complete the review, given some of these relationships have not yet been established yet, ideas for further research are proposed.

\section{NASAL HEAT AND MOISTURE EXCHANGE}

Within the nose, there are interactions between independently regulated systems (Fig. 1) in order to control nasal air-conditioning. Nasal air-conditioning requires heating and water mass transport systems operating in conjunction with an efficient mucus propulsion system. Regulation of these two fluxes is achieved through the combined actions of the nasal autonomic nervous system and epithelial cell fluid transport. Over a 24 hour rest period, healthy humans normally breathe around 10,000 liters of air which is typically supplemented with around $400 \mathrm{ml}$ of water and $1470 \mathrm{~J}$ of heat energy when breathing ambient air at $25^{\circ} \mathrm{C}$ temperature and $50 \%$ relative humidity $[21,22]$. During quiet breathing, in vivo measurements across the nasal cavity show increased air temperature and humidity levels in an anterior to posterior direction during both inhalation and exhalation [22].

The nasal fluid lining plays an important role in terms of water and heat transfer during the breathing cycle [23]. The temperate inspired air, aided by turbulence, is heated and humidified as it passes through the nasal cavity, causing the mucosa to cool when water transfers from the airway fluid to the air. However, during exhalation, some of the moisture from the fully saturated air at core body temperature condenses on the nasal mucosa which has been cooled during inhalation. Exhaled moisture is captured for use in humidification during the next breathing cycle. The cyclic exchange of latent and sensible heats as 
1 well as the partial water recovery implies that the nasal fluid lining acts as a buffer zone between the nasal

2 air and the underlying epithelial layer supplying water and heat. This buffering effect possibly reduces the transient fluid requirement from secretion glands and stabilizes cyclic thermal fluctuations during normal breathing. It may also offer protection from hot air damage due to the fact that it has a higher sensible heat capacity than air [18]. The nasal airway fluid lining also provides a platform for mucus transport [2426], particulate entrapment and absorption of gaseous water soluble air contaminants [27, 28].

8 Mucociliary transport of airway fluid is achieved by the synchronized beating of cilia protruding from pseudo-stratified columnar epithelial cells located in the airway mucosa. Cilia, normally beating around 10-20 Hz in the thinner 5-7 $\mu \mathrm{m}$ thick PCL layer, engage the thicker gel layer [29] with a whip-like motion [30-33]. The primary function of the upper mucus gel layer is particulate entrapment. Over time this layer progressively forms into globules, which coalesce into small flakes and subsequently larger plaques. Continuous transportation of the mucus layer towards the nasopharynx, where it is cleared by swallowing or expectoration, is essential not only for removal of entrapped contaminants [28, 34], but also for nasal air-conditioning [18]. Insufficient MTV may lead to an increase in airway fluid depth or a build-up of coalesced mucus hindering both heat and water exchange. On the other hand, excess airway surface liquid transported from the lower lungs is absorbed by the epithelial cells [34].

Airflow regimes also play a significant role in heat and water mass transport. The nasal valve region, anterior to the inferior turbinate, provides a major dynamic portion of nasal airflow resistance. This region is thought to create turbulent airflow, which enhances heat and water mass transportation [35, 36]. Widening of the air passage posterior to the turbinates with subsequent slowing of airflow enables deposition of particulate matter. Although the nose provides about $90 \%$ of respiratory system airconditioning requirements [37, 38], further humidification and heating of the inhaled air occurs as it travels through the pharynx and trachea. Fluid lining in these regions provides heat and moisture until the air becomes fully saturated at core body temperature at a position termed as the isothermic saturation boundary (ISB) [18]. The thermal and humidity gradient experienced by the inhaled/exhaled air, along with the ISB location, fluctuate over the breathing cycle. Changes in ambient air temperature and humidity also cause changes in ISB location. 
1

2

3

4

5

6

7

8

9

\section{AUTONOMIC REGULATION}

Regulation and control of any process requires sensing. The thermo-receptors, concentrated around the vestibule, are believed to be the main sensors of inhaled air temperature. However, non-specific nasal innervation provides the ability to achieve strong tissue reactions, such as the sneezing reflex, under both normal and pathological conditions [39, 40].

\section{6}

Modulation of the nasal vascular flow by the autonomic nervous system regulates heat and fluid supply to the glands [41, 42] and adjusts airflow regime to meet air-conditioning demands [22, 43]. The ability of a healthy nose to condition extremes of environmental air to near alveolar conditions requires control of the heat and water fluxes across nasal mucosa. Achieving this requires simultaneous regulation of control of air flow regimes regulating heat and water mass transfer to and from the air, mucosal heat and water supply to airway fluid, as well as effective airway fluid transportation. These parameters are autonomically regulated through sympathetic and parasympathetic innervation [42], along with nonadrenergic, non-cholinergic gas signaling [44]. The control induced by this gas signaling process differs from that produced by the sympathetic and parasympathetic nervous innervation in a sense that it utilizes nitric oxide (NO) as a neurotransmitter [42, 44, 45]. NO is produced throughout the respiratory tract by the epithelial mucosa [33, 46-48]. Different isoforms of NO synthase occur within the respiratory tract under normal and pathological conditions [44]. For example, inducible nitric oxide synthase (iNOS) may assist microbiological defenses whilst endothelial nitric oxide synthase (eNOS) assists vasodilatation. Under normal conditions, nasal nitric oxide (n-NO) production is regulated through the absorption and synthesis of air-borne $\mathrm{O}_{2}$ by the nasal epithelial cells [49]. The output of n-NO is proportional to airflow [46, 50]. From an air-conditioning perspective, vasodilators (such as n-NO [47, 51]) or vasoconstrictors (such as antihistamine [52, 53]), either absorbed from the inhaled air or circulated within the blood, can influence blood flow within the nasal vasculature [54].

\section{Airflow Regime}

Within each nasal passage, the regulation of turbinate volume controls the airflow cross-sectional area (CSA), causing variation in the air velocity and flow regime that regulates heat and water mass flux. Commencing at the anterior region, during rapid inhalation, the CSA of the vestibule or "external nasal valve” is stabilized by cartilaginous tissue and inspiratory isometric contractions of the alar dilator 
muscles which results in a relatively constant restriction to airflow [36]. The incoming airflow meets the highest resistance when it reaches 'the internal nasal valve' region. Before entering the larger cavernous nasal space, the incoming laminar flow accelerates as it passes through the reduced CSA, creating turbulent airflow which enhances heat and water transfer within the nose [36, 55, 56].

Autonomic regulation of outgoing and recovered nasal fluid heat and water flux is realized through changes in intranasal airflow resistance causing variation in air velocity distributions within each nasal passage $[57,58]$. This is achieved through independent regulation of blood flow through the cavernous plexus or nasal erectile tissue found predominantly in the inferior turbinates and opposing septal wall [36, 56, 59]. This tissue consists of a network of large anastomosing veins capable of rapid blood volume changes through the cushion or throttle activation in the regulating drainage veins [40]. Airflow constriction occurs when the anterior end of the inferior turbinate projects into the nasal valve region, causing a reduction in CSA [36]. The dynamic behavior of the internal nasal valve is demonstrated by its erectile tissue reflex which can be initiated by applying pressure to one side of the body on a single armpit or simply by lying on one side [60,61]. Both of these situations result in blocking of the nasal passage on the side on which the stimulation was applied. The functional purpose of this autonomic reflex, mediated by skin pressure receptors, minimizes sweating on the downside of the body when lying on the side, however, the regulation of the nasal erectile tissue appears altered as well. This reflex demonstrates that regulation is at a central level, since other autonomic functions on the corresponding side are also affected [62].

Part of nasal autonomic regulation involves 'the nasal cycle', which is a periodic congestion/decongestion process of the erectile tissue alternating from one side of the nose to the other [63-65]. The cycle periods range from 10 minutes to 8 hours and usually go unnoticed since the total nasal airflow resistance remains unchanged [22, 42]. This variation in intranasal airflow patterns occurs in $20-40 \%$ of the population [58, 59] and coincides with an increase in fluid secretion in the patent side, but does not influence the degree of water vapor saturation in the inhaled air [58, 63]. Currently it is thought that n-NO concentration increases on the obstructed side, but in general the role n-NO plays in the nasal cycle remains uncertain [66]. The duration of this ultradian cycle positively correlates with vasoconstrictor sympathetic outflow and has been assessed by measuring the difference in brain hypothalamic and ear pinna temperatures in 
1

cats [67]. In humans, electroencephalography (EEG) has demonstrated an alternating dominance in cerebral hemispheric activity that correlates directly with the nasal cycle $[58,62,68]$. The purpose of the nasal cycle is not fully understood; however, it may control the balance between heat and water fluxes from the airway fluid lining [69], as well as enable cells and glands on the constricted side to rest and recharge [42].

\section{Mucosal Heat and Water Supply}

A sub-epithelial network of fenestrated capillaries, positioned parallel to respiratory epithelium, supply both heat and humidification within the nose [40, 70]. At least half of the nasal blood flow passes through arteriovenous anastomoses (AVAs) which are connections between two blood vessels. These provide an alternative flow path during periods of congestion in erectile tissue. The role of AVAs is related to temperature and water control in the same way as in other parts of the body, such as in the hands and feet [70]. Mucosal blood flow is under autonomic nervous control with sympathetic nerves causing vasoconstriction and parasympathetic nerves dilatation [58]. The vasodilatory effect of n-NO contributes to the regulation of nasal blood flow by providing an additional means of controlling airway fluid secretion and heating [51, 71, 72].

The airway epithelium actively absorbs fluid, however, the estimated rate of submucosal gland secretion is significantly greater [73] which results in a net airway fluid gain. Submucosal gland mucus secretion and the depth of underlying PCL are regulated by autonomic mechanisms [40, 70, 74, 75]. Purinergic cellular fluid release and absorption also contribute to airway fluid volume regulation [26, 76]. Here fluid release occurs during multiple stress stimuli [77] and in response to airway fluid $\mathrm{Na}^{+}$and $\mathrm{Cl}^{-}$balance [24, 26].

\section{Airway Fluid Transportation}

During a breathing cycle, there is a continual flux of water and heat between the nasal airway fluid layer and inspired and expired air (Fig. 1). This fluid layer is a thermal and fluid buffer as well as a sink that traps inhaled particulate matter and water soluble toxins. The MTV normally ranges from 3 to $25 \mathrm{~mm} / \mathrm{min}$ and it moves airway fluid toward the nasopharynx to ensure contaminant clearance and prevention of an excess mucus plaque build-up, which could obstruct water exchange between air and the PCL layer. 
1 Changes in PCL rheology, tonicity, adenosine tri-phosphate (ATP) concentration, mucus depth and cell

2 temperature all influence ciliary beat frequency (CBF) [18, 29, 77-81], which in turn affects the MTV.

3 Recent research has found that n-NO also plays an important regulatory role in nasal air-conditioning

4 through regulation of CBF [47, 48, 82, 83], airway fluid transportation [71] as well as vascular derived

5 fluid and heat output [72]. CBF is, however, primarily regulated through purinergic pathways.

6

\section{PURINERGIC REGULATION}

8 Whilst most nasal mucus is produced by airway glands that respond to acetylcholine and vasoactive intestinal peptide [84], it is also secreted from goblet cells. Airway epithelial cells respond, through receptors and channels, to extracellular molecules and ionic concentrations that result in the blocking, or secretion/absorption of specific fluids passing through the cell membrane. These receptors and channels form the purinergic regulation system. Dynamic regulation of mucin secretion by goblet cells into the mucus layer, release of intracellular ionic fluids that make up the PCL and cilial driving action are all thought to be achieved through epithelial cell purinergic pathways [85]. As breathing stimulates nucleotide activation and ion transport that achieves periciliary fluid volume regulation, the following review is presented in this sequence.

\section{Breathing Stimulation}

Intracellular ATP release is triggered by mechanical deformation [86, 87], fluid shear stress [88, 89] and compression or stretch of human airway epithelia [90, 91]. Extracellular release of this signaling molecule occurs during oscillatory pressure fluctuations generated during normal tidal breathing. This stimulus is important in the regulation of mucus clearance and the maintenance of a healthy airway [89, 91]. ATP and other nucleotides from the airway epithelia are released by mechanical forces [26, 92] which are imparted by breathing-induced cyclic shear and pressure stress which is exerted on the airway fluid layer and oscillatory trans-epithelial pressure fluctuations [26]. Experimental work on tracheal epithelia has shown that ATP release rates are most sensitive over the normal physiological range of oscillatory shear and compressive stress [26]. While the airway wall shear stress during normal breathing is estimated as high as $3 \mathrm{dyn} / \mathrm{cm}^{2}$ in the nose [93] (compared to around $0.45 \mathrm{dyn} / \mathrm{cm}^{2}$ in the trachea and lower airway [89]), it is likely that the nasal epithelium responds to airway stresses in a similar fashion to the trachea. 
4 Recent work on sheep trachea has found that fully humidified unidirectional airflow at $30^{\circ} \mathrm{C}$ or even $34^{\circ} \mathrm{C}$

an increase in CBF [85, 94-98], this stimulation is also considered part of a natural nasal defense system to wash away noxious stimuli $[77,96]$.

is insufficient to prevent epithelial cell dysfunction or damage from occurring [99]. During normal tidal breathing healthy nasal epithelia is exposed to air well below these temperatures and humidity values. This highlights the importance of cyclic air-stress stimulation in maintaining healthy ASL volume and MTV.

\section{Nucleotide Activation and Ion Transport}

PCL volume regulation is achieved by activation of two classes of receptors, P1 and P2, in response to extracellular stimulation by nucleotides and their metabolites [96], see Fig. 2. This activation opens pathways to regulate specific ionic fluid transport across the epithelial cell wall. Currently, all four known P1 receptors, $A_{1}, A_{2 A}, A_{2 B}$ and $A_{3}$, are primarily activated through adenosine [77, 85]. This metabolite is derived from ATP that has been converted to adenosine mono-phosphate (AMP) and then adenosine via hydrolysis by ecto-nucleotidases present on the cell surface $[96,100]$. Activation of the $A_{1}$ or $A_{3}$ receptors releases intracellular $\mathrm{K}^{+}$and $\mathrm{Cl}^{-}$into the surrounding fluid. Variation in intracellular calcium $\left(\mathrm{Ca}^{2+}{ }_{\mathrm{i}}\right)$ occurs when a subgroup of P1 receptors, type 2Y, couple to a signal enzyme phospholipase C (PLC), forming inositol 1,4,5-trisphosphate $\left(\mathrm{IP}_{3}\right)$. This acts as a secondary messenger molecule, releasing $\mathrm{Ca}^{2+}{ }_{\mathrm{i}}$ from internal stores [94]. P1 receptor activation produces a discharge of intracellular fluid and an elevated CBF $[78,101]$. However, activation of $\mathrm{A}_{2 \mathrm{~A}}$ and $\mathrm{A}_{2 \mathrm{~B}}$ receptors releases intracellular $\mathrm{Cl}^{-}$ions and produces the same increase in intracellular $\mathrm{IP}_{3}$ levels that releases $\mathrm{Ca}^{2+}{ }_{\mathrm{i}}$, producing elevated CBF.

Of the sixteen known $\mathrm{P} 2$ receptors, there are eight metabolic (P2Y) receptors, $\mathrm{Y}_{1}, \mathrm{Y}_{2}, \mathrm{Y}_{4}, \mathrm{Y}_{6}, \mathrm{Y}_{11}, \mathrm{Y}_{13}$ and $\mathrm{Y}_{14}$. All are activated when extracellular concentrations of the nucleotides ATP, uridine 5'-triphosphate (UTP) or their metabolites, ADP, UDP and UDP-sugars, reach sufficient concentrations [77, 102]. Like the P1 receptors, activation of the $\mathrm{P} 2 \mathrm{Y}$ group elevates intracellular $\mathrm{IP}_{3}$ levels, which releases $\mathrm{Ca}^{2+}$, elevating CBF, whilst simultaneously signaling the opening of channels that release intracellular $\mathrm{K}^{+}$[103] and $\mathrm{Cl}^{-}[104,105]$ into the surrounding PCL. It is believed that a $\mathrm{Ca}^{2+}{ }_{\mathrm{i}}$ independent $\mathrm{Cl}^{-}$channel exists [96] and that the $\mathrm{P}_{2} \mathrm{Y}_{2}$ and $\mathrm{A}_{2 \mathrm{~B}}$ receptor groups have one of the strongest influences on $\mathrm{CBF}$ and airway ion 
1 and water transportation [100, 101, 106-108]. Eight P2X receptors, triggered exclusively by ATP [77,

2 85], increase cell membrane $\mathrm{Ca}^{2+}$ and $\mathrm{Na}^{+}$permeability [77, 104].

3

\section{$4 \quad$ Periciliary Liquid Volume Regulation}

5 Airway epithelia, characterized as having low transepithelial resistances [109] and high water 6 permeability [110-112], finely tunes the PCL hydration state [113]. This is achieved through continual 7 back-flux occurring during cellular ion and water release [26]. Leaky epithelia are capable of absorbing 8 fluid through $\mathrm{Na}^{+}$absorption and discharging fluid through $\mathrm{Cl}^{-}$secretion. The PCL $\mathrm{NaCl}$ concentration is 9 essentially isotonic with the epithelial cell [114]. It has been hypothesized [26, 115] that salt secreted by the epithelia is followed by water, to maintain tonicity, resulting in a PCL volume increase. Conversely, if salt is absorbed by the epithelia, water will follow into the cells, resulting in PCL dehydration. Data shows continuous switching of these ion channels between secretion and absorption phenotypes [89, 113]. Epithelial water flux possibly fine tunes PCL volume during tidal breathing.

\section{MODELING}

Heat and mass flow are essential for any air-conditioning process. Local heat and water mass transfer coefficients have been reported utilizing naphthalene sublimation techniques [116]. However, nowadays, computational techniques, such as computational fluid dynamics (CFD), are commonly used to predict these coefficients.

Simulation techniques of airflow, heat and water mass transfer are used to understand the influence of morphology and mucosal conditions on nasal air-conditioning and also to predict the influence of surgical interventions. Early ex-vivo physical models in cadaver half heads or casts visualized flow through transparent plates, which replaced the septum [117]. Although this technique was troubled by uncontrollable cadaver tissue shrinkage, it provided qualitative visualization of airflow patterns through smoke particles in air or dye filaments in liquid [22, 55, 117, 118]. Later the use of plastination overcame the problems associated with tissue shrinkage [119]. .Quasi-static one-dimensional theoretical models developed to predict heat and water mass transfer [120] compare well with the temperature profile measured with in vivo studies [121]. Later two and then three dimensional computational studies utilizing simplified nose-like features enabled local determination of air temperature and humidity [122, 123]. On 
1 the other hand, quantitative measurements within cadaver models using both laser Doppler velocimetry

2 and miniature hot-wire anemometry enabled discrete air velocity measurement. Digital particle image

3 velocimetry now suggest-that the 2-D approach does not provide an accurate representation of the

4 complex 3-D airflows present within the complex nasal cavity [22].

5

6 Modern computer tomography (CT) and magnetic resonance imaging (MRI) techniques enable the 7 capture of subject specific in vivo 3-D digital sectional nasal images [117, 124-126]. These techniques

8 avoid the problem of cadaver tissue shrinkage encountered in ex-vivo physical testing and provide 9 accurate complex nasal topographical data for use in computation fluid dynamic (CFD) models. Implementing four differential equations of conservation of mass, momentum, convection-diffusion and thermal energy balance into CFD modeling enables determination of instantaneous spatial distribution of air velocity, pressure, temperature and water vapor concentration along with heat and water flux [22, 122]. Mesh-based CFD models require sharp gradients in mesh density to maintain an anatomically correct model. This poses difficulties in mesh refinement if accurate results are to be obtained in these regions; however, the use of non-mesh based CFD overcomes this issue [117].

Assumptions of constant temperature and nasal wall water vapor concentrations commonly applied to CFD models ignore the spatial and time dependent distribution of the surface/gas interface and of the bulk fluid circulation [127]. Whilst some early CFD studies assumed steady airflow, during normal breathing the cyclic airflow causes variation in wall shear stresses and temperatures as well as in intranasal temperature $[69,128]$. However, unsteady simulation utilizing 3-D CFD models overcomes this issue and supports previous estimates that the nose provides $90 \%$ of the heat and water flux required to modify inhaled air to alveolar conditions over an extreme range of ambient air temperature and humidity [122]. These results suggest that nasal air-conditioning is virtually independent of environmental conditions which is in support of previous in vitro studies [69]. On the other hand, pressure-flow measurements utilizing plastinated human facial specimens are comparable with those obtained by CFD techniques [119]. Ex-vivo plastinated and physical modeling along with CFD techniques have identified the nasal valve region as having the greatest influence on heat and water mass transfer due to induced higher airflow velocities [117, 119-121, 124-126, 128]. 
1 Recent CFD modeling of gas exchange between the maxillary sinus and nasal cavity predicted that for

2 small single sinus ostia and large concentration gradients, diffusion was the dominant mechanism for

3 sinus NO transport mechanism [129]; while for larger ostia and lower concentration gradients, convection mass transfer became dominant. Although modeling of n-NO content relative to nasal air pressure cannot be found in current literature, 3-D simulations utilizing a $6 \mathrm{~mm}$ diameter ostium considering both diffusion alone and combined diffusion/convection produced results that matched testing of physical models [129].

An early clinical breathing therapy humidification model proposed that maintenance of optimum airway fluid rheology was necessary in order to achieve optimum mucociliary transportation [18]. This model, which includes tracheotomy breathing, assumed that inspired air temperature and humidity were the sole factors influencing airway fluid transportation and rheology. No mention was made of air pressure and this model in effect disregarded the air-conditioning contribution from the nose and trachea. Mathematical modeling of mucociliary clearance fluid mechanics that consider cilial beat cycle, CBF, metachronous coordination and airway fluid rheology have been utilized to predict MTV [30]. Nasal wall distention under pressure has also been modeled [130] and was used to predict changes in airflow velocity during breathing at elevated air pressures. Numerous models utilizing fixed geometry of airway heat and water transfer have been undertaken [116, 120, 131-133], however, to the best of our knowledge, none considers the influence of many variables, such as changes in geometry and cell air stress-stimulation, due to breathing therapy air pressure on nasal air-conditioning.

\section{AIR-CONDITIONING PATHOPHYSIOLOGY}

The mechanisms through which nasal breathing therapy influences the efficacy of the nose to heat and humidify inhaled air are poorly understood. Pressurized breathing therapy, utilizing ambient air, frequently invokes negative nasal side effects. This suggests that the nasal mask conditions, in particular pressure, may be a contributing factor. However when reviewing patient symptoms, care needs to be given to subjective sensations. For example, perceived nasal patency may not be a reliable indicator of nasal congestion [134]; nasal inhalation of menthol triggers the sensation of improved nasal patency while airway resistance remains unchanged [59]. Compounding the difficulty in achieving reliable information is the buffering effect of the airway lining liquid, which produces a time delay between heat and water supply and loss/recovery to nasal air. A recent study has found no correlation between the 
1 applied air pressure and the efficacy of nasal air-conditioning or related nasal symptoms during n-CPAP

2 therapy [135]. However, testing was only undertaken over a 20-minute period and nasal airway liquid

3 reserves probably made up for the shortfall in supply. An apparent contradiction to this suggestion is

4 found in research into the long-term effects of n-CPAP therapy [28]. No changes in nasal resistance,

5 mucociliary clearance or CBF was found before or after the application of long term breathing therapy.

6 Researchers suggested that n-CPAP use might aggravate nasal inflammation, but unfortunately no data

7 was collected during breathing therapy. In this study, the nasal mucosa may have recovered after

8 cessation of treatment.

9

10 Mucosa Heat and Water Supply

11 The sub-epithelial network of fenestrated capillaries, positioned parallel to and facing the respiratory 12 epithelium, are considered the humidification and heating source within the nasal cavity [40]. Nasal vascular beds making up the erectile tissue, glands and radiator vessels have a complex interlinking vasculature and nerve signaling structure [42]. This complexity makes it very difficult to identify discrete pathway or sensory regions responsible for changes in the mucosal heating and water state. Little information is available on the controlling mechanisms, both in terms of the affecting variables and sensors regulating heat and water transport within the nasal airway tissue layer. However, the vasodilatation effect of n-NO is thought to have a regulatory role in nasal air-conditioning [72, 136, 137].

Body position influences nasal air-conditioning with improved water availability and air heating sitting upright when compared to a supine position [138]. This is in contradiction with what researchers had predicted, namely, in the supine position, an increase in nasal blood volume in the venous sinuses occurs simultaneously with increased heat and water flux. The increase in nasal resistance, as indicated by a reduction in nasal volume due to swelling of nasal erectile tissue, does not appear as a consequence of increased nasal blood flow [43]. It seems that the capacitance vessels located deeper within the mucosa regulate nasal resistance and are independent of blood flow in the superficial mucosa layer which provides heat and moisture. This disassociation confirms earlier work on dogs, which concluded that nasal airway resistance cannot be correlated to vascular resistance or blood volume [139]. These results suggest that different parts of the mucosa respond differently to the same stimulus, such as changing body position. However the actual mechanism by which this occurs has not yet been established. 
2 Perceived nasal dryness and the formation of mucus crusts may occur when water loss from the airway fluid exceeds its supply [40]. A possible cause is a reduction in the number or damage to the fenestrated capillaries within the nasal cavity. However, this does not explain why the use of nasal breathing therapy could cause these symptoms. On the other hand, vasomotor or non-allergic rhinitis, where nasal blood vessels dilate causing the nasal lining to fill with fluid and blood, is thought to occur as a consequence of excessive nasal fluid secretion [40, 140]. A change in the regulation of the musculature of these vessels is readily achieved through exposure to agents, such as vasodilators, circulating in the blood or by stimulation of the adventitial nerve endings in the outer blood vessel layer. Stimuli such as temporary humidity changes, ingestion of alcohol, infection, weather changes, stress, airborne irritants, medication and hormonal changes may all contribute to rhinitis [141-144]. Further, a reduction in plasma extravasation in airway epithelial cells, due to elevated air pressures, is believed to be due to a hydrostatic pressure-operated mechanism [145]. These findings in saline and histamine challenged mucosa may have no bearing on PCL supply in healthy mucosa during nasal breathing therapy.

A link exists between the ultradian nasal and sleep cycles which may influence nasal air-conditioning during breathing therapy [58, 62, 64, 68]. While awake and during synchronized or non-rapid eye movement (n-REM) sleep, vascular heat exchangers, including those found in the nasal mucosa, regulate body temperature through autonomic sympathetic vasoconstriction [67]. During desynchronized or rapid eye movement (REM) sleep, the pressure difference across the vessel walls tends to regulate blood flow with autonomic control becoming dysregulated, but not absent. During this sleep period, applied air pressure could reduce nasal vascular flow rates. This hypothesis is supported by the use of negative pressure to treat erectile dysfunction by facilitating an increase in blood flow to the penis [146, 147]. The effect elevated air pressure has on the nasal erectile tissue vasculature is not yet known.

\section{Airway-Fluid Transportation}

27 Efficient transport of the airway fluid is important in matching the heat and water flux gradients from the underlying cellular and glandular structures to cyclic airflow humidification requirements. Airway fluid transportation is provided by coordinated cilia beating at a frequency influenced by many factors including n-NO concentration [47, 48, 82, 83]. Allergic rhinitis increases n-NO levels but this is 
1

2

3

4

5

6

7

8

9

decreased in chronic sinusitis [33]. An increase in airflow through the nose also increases n-NO release with higher levels occurring during inhalation than exhalation [50,71], but due to lower airflow rates, lower release occurs during sleep [148]. Since n-NO production is modified by changes in nasal blood flow and nasal volume [48], this may well be in response to a greater air-conditioning demand being made on the nose during periods of high air flow. On the other hand, humming increases n-NO concentrations 5-15 fold when compared to silent breathing and this effect diminishes when repeated [47, 48, 149-151]. Physical variables such as the nasal cavity volume, posture and airflow resistance do not change n-NO levels whilst smoking, hypoxia, intense exercise and the use of NO synthase (NOS) inhibitors and decongestants cause a reduction [47]. It is believed that L-arginine supplementation is useful in increasing NO concentrations in some patients [83]. Hyperbaric research [152] has demonstrated a $16 \%$ reduction in n-NO levels during periods when breathing air elevated to a pressure of $49 \mathrm{~cm}_{2} \mathrm{O}$. This is more than twice the maximum pressure normally experienced during CPAP therapy. Further, occlusion of the sinus from the nasal cavity could prevent sinus sourced NO from entering the nose space, leading to subnormal n-NO levels in some situations. Soft nasal erectile tissue has frequently been found in the regions adjacent to openings of the paranasal sinuses where the mucosa has formed a lip or margin [40].

CBF appears to be related to changes in epithelial cell size. In murine tracheal tissue, reduction in cell size and CBF correlates directly with changes in extracellular fluid tonicity [81]. Water loss reduces CBF whilst re-hydration restores this action. CBF decreases under hypertonic conditions and conversely increases after dilution to hypotonic levels. This occurs with a range of osmolytes, including sodium chloride, mannitol, xylitol, glucose, cesium chloride and ethanol. The demonstration of hypotonic stimulation is consistent with the finding that cell swelling stimuli causes extracellular ATP or UTP release [81, 96]; this is a known purinergic regulator of CBF [78]. Mechanical stimuli, possibly through elevated airway pressure forces, are also known to initiate this release [77, 96]. This could adversely influence the epithelial purinergic pathways regulating CBF and ion transport across the epithelial cell boundary. As previously mentioned; in healthy subjects the airway surface liquid is approximately isotonic, resulting in equal ionic concentration existing across cellular walls [114, 115]. Epithelial cell damage changes the ion content in the connective tissue of the airway walls [153], reinforcing the view 
that cell stimuli or damage may induce intracellular ATP or UTP release, leading to dysfunction of epithelial cell purinergic pathways.

Air pressures of up to $20 \mathrm{~cm} \mathrm{H}_{2} \mathrm{O}$ are delivered during n-CPAP therapy [9] which is well above the normal pressures of around -0.1 to $+0.3 \mathrm{~cm} \mathrm{H}_{2} \mathrm{O}$ experienced across a healthy nose during normal oscillatory breathing $[117,119,154]$. This significant pressure augmentation effectively exposes the epithelial cells to a non-oscillatory stress that could interrupt normal ATP or UTP release [26], disrupting normal purinergic regulation, and cause reduction of airway fluid levels and CBF.

An investigation into the morphological changes that occurred in the nasal mucosa of patients undergoing n-CPAP therapy over a 3-10 month period has found that the epithelium in all patients underwent fundamental changes [6]. These included epithelial cell shape changes as well as cilial clumping and conglutination. However, this was contradicted by a later investigation [28] which made the influence breathing therapy has on the nasal mucosa morphology yet unclear.

Exposure to temperature extremes also impacts negatively on $\mathrm{CBF}$; below $5^{\circ} \mathrm{C}$, $\mathrm{CBF}$ virtually ceases [155] while above $50^{\circ} \mathrm{C}$, epithelial cell death occurs [156]. Exposure to cold dry air can lead to epithelial shedding with symptoms of rhinitis, rhinorrhea and nasal congestion in people sensitive to temperature stimuli [157]. This shedding occurs due to a relaxation response, induced by cooling, occurs in the nasal mucosa [158].. These temperature extremes are not normally encountered during breathing therapy.

Nasal breathing when compared to oral breathing has an important role in maintaining upper airway mucosal "wetness" [159, 160]. Airway fluid rheology plays an important role in mucosal transport [80]. One clinical model concluded that air inhaled during breathing therapy needed to be fully saturated at core body temperature to maintain the mucociliary transport system in an optimum state [18]. This recommendation was made for tracheotomy patients, where the main airway source of heat and moisture had been by-passed, and also for CPAP users. For this situation, progressive reduction in airway humidity causes fluid thickening, a slowing of MTV [29, 161, 162], a reduction in CBF and epithelial cell damage. Under extreme conditions, low fluid levels within the lungs could lead to atelectasis and poor gas exchange [18]. On the other hand, progressive over humidification causes thinning of the airway fluid and 
1 a slowing of MTV due to a reduced cilia driving force. If prolonged, this leads to cessation of fluid

2 transport and the risk of fluid draining into the lungs [18]. In extreme cases epithelial cell thermal damage

3 could occur due to excess condensation. A prolonged exposure time outside the optimum range could

$4 \quad$ lead to more severe consequences.

5

\section{$6 \quad$ Heat and Water Convection Coefficient}

7 The rate of heat and water vapor transfer occurring between the nasal mucosa and respiratory air throughout the breathing cycle is governed by the corresponding convection coefficient. Airflow velocity has a significant influence on these coefficients and is dynamically regulated in each nasal passage through engorgement of erectile tissue, located in the nasal valve [36].

Congestion of the turbinate mucosa increases air turbulence which serves to enhance heat and water mass flux [59]. Additional heat from the engorged turbinates and surrounding erectile tissue was thought to enable the inhaled air to achieve further moisture acquisition within the nasal cavity. Recent simultaneous MRI, temperature and humidity measurements within the nose have contradicted these earlier ideas by suggesting nasal patency is independent of air-conditioning within the normal levels of turbinate volume change [163]. During the breathing of ambient air, variation in the middle and inferior turbinate volumes was found not to have a significant influence on intranasal air temperature and humidity levels. Although the range where changes in turbinate volume influences nasal air-conditioning was not established, the study confirms the possibility of both purinergic and autonomic regulation systems working together to regulate nasal air-conditioning. Even though the study did not examine the effect of nasal air pressure, it showed that variation in turbinate volumes may play a greater role in congestion than in heating and humidification.

As previously stated, the purpose of the nasal cycle is not fully understood but it likely controls the balance between heat and water fluxes from the airway fluid lining [69], as well as enable cells and glands on the constricted side to rest and recharge [42]. The cycle may be affected by several factors including body position. Given a shift in position, from lying flat to sitting upright having less influence on the nasal cycle than a shift from lying flat to lying on the side [60], changes in posture have a 
1 significant role in determining the airflow through the nose by. Positional changes may also disrupt cell

2 and gland recuperation periods by forcing change in duration of the nasal cycle.

3

4 Changes in nasal airflow resistance between upright and supine positions have been attributed to 5 increased venous pressure reducing venous drainage from the erectile tissue located in the nasal valve region [42, 43, 60]. Nasal venous pressure increases by $8 \mathrm{mmHg}$ between the upright and supine positions [59]. However, the air pressure used in breathing therapy can exceed this value and cause compression of soft erectile tissue and may result in suppression of blood flow in these regions. In support of this is the finding that a significant proportion of patients who undertake n-CPAP therapy experience an increase in nasal valve area and volume[4]. Both of these parameters have a significant influence on nasal airflow velocity and subsequent variation in local heat and water mass transfer coefficients within the nose.

Vasomotor, non-allergic and allergic rhinitis are thought to cause nasal congestion due to erectile tissue swelling $[40,59]$. The influence this has on autonomic regulation is not well established. However, the nasal congestion in most cases can spontaneously resolve through the application of a vasoconstrictor, such as an $\alpha$-agonist, indicating that the swelling is due to changing the vascular capacitance rather than the accumulation of extra-vascular fluid [36]. The congested side of the nose tends to have a higher total water content than the non-congested side [140].

The influence that the nasal blood flow can have on the nose is seen in postcoital rhinitis, commonly termed 'honeymoon rhinitis', which occurs when sexual excitement elicits sneezing, rhinorrhea and nasal obstruction immediately after sexual intercourse $[164,165]$. Although hyperventilation may cause nasal congestion, the exact cause of this phenomenon remains unknown. Engorgement of the nasal erectile tissue may occur as part of a nervous response, which includes sexual arousal [166]. 
1 Transmural pressure regulates vascular flow during desynchronized or REM sleep [67] and also reduces

2 ultradian cycle duration. Elevated air pressure may influence nasal vascular flow causing disruption to

3 nasal air-conditioning. Reduction in sleep quality could perhaps explain partly the high level of

4 dissatisfaction and non-compliance with n-CPAP therapy. Nasal breathing is designed to alternate from

5 side to side in an ultradian cycle. Forced unilateral nostril breathing can influence this cycle at a central

6 level $[167,168]$. Both the influence of the lack of alternating nasal flow on the dream cycle, which is

7 necessary for quality sleep, and the effect of n-CPAP therapy has on brain wave patterns during sleep

8 remain unknown.

\section{FUTURE INVESTIGATIONS}

In a healthy airway there are many parameters that serve to regulate the efficacy of the nose to condition inhaled air. These include, but are not limited to airway fluid transportation, airflow regulation, heat and fluid supply. Each serves to regulate the efficacy of the nose to condition inhaled air and is seemingly influenced in some way by nasal mask air pressure. By isolating and trending their respective pressure related response, a better understanding of the effect of air pressure can be established.

\section{Airway fluid transportation}

Decoupling the influences of n-NO and epithelial stress stimuli induced ATP release on CBF driving mucociliary transportation of the mucus and PCL is problematic. It is not known yet how CBF is influenced when acted upon simultaneously by both of these variables. Intranasal n-NO concentration is a function of airflow rate and it appears influenced by nasal cavity air pressure. Currently, n-NO concentrations as a function of breathing cycle phase [71], flow rate [46] or under hyperbaric condition [152] are known. However, an in vivo measurement of n-NO in vivo as a function of applied breathing therapy pressure over the breathing cycle is required.

The suggestion that CBF is suppressed by excessive pressure leading to an excessive cell stress stimulus [81], needs to be confirmed, along with the relationship, if any, between CBF and applied breathing therapy air pressure. This could be achieved through recording airway liquid levels and particle transport velocity during in vitro nasal tissue pressure stress stimuli. Further investigation is also required to 


\section{Airflow Regulation} during breathing therapy.

\section{Heat and Fluid Supply}

\section{Clinical Implications}

establish if changes occur in airway fluid tonicity as well as extracellular ATP and other nucleotides

The heat and water mass transfer convection coefficients are strongly influenced by the airflow regime present within the anterior region of the nose. Airflow is regulated through activation of erectile tissue in the nasal valve region. Venous pressure used to achieve this activation has a range similar to that applied by some nasal breathing therapies [59], so air pressure may influence erectile tissue regulation. This could be investigated through the use of MRI to measure the in vivo changes in nasal morphology that occur between breathing ambient and pressurized air.

Changes in nasal vasculature flow supplying mucosal heat and water could occur due to the vasodilator effect of n-NO as well as from the influence of air pressure acting on soft mucosa tissue creating venous flow constriction. Decoupling of these variables during in vivo testing will be difficult, however, any influence n-NO and air pressure have on the nasal vasculature needs further investigation. Despite research finding reduced plasma extravasation occurring during elevated air pressures [145], further work is required to determine if this occurs in healthy mucosa during nasal applied breathing therapy. MRI perfusion techniques could be utilized to quantify pressure induced change in nasal vasculature flows.

Airway fluid tonicity appears to be linked to epithelial stress stimuli in the regulation of airway fluid layer height. Investigations using in vitro nasal tissue exposed to pressure stress stimuli and simultaneous tonicity measurement could improve our understanding of airway water supply.

Using nasal mask conditions to supplement any shortfall in nasal air-conditioning requires an understanding of the effect air pressure has on the regulatory systems. Investigations into nasal airway fluid transportation, airflow regulation and heat and fluid supply may lead to a therapy temperature/pressure/humidification algorithm that optimizes these parameters for a prescribed therapy pressure. Optimization could lead to a reduction in titration pressure and improved treatment compliance. 
1 Until further work is undertaken to improve our knowledge in this area, the requirement to deliver fully

2 saturated air heated to core body temperature remains the safest treatment option.

3

\section{ACKNOWLEDGEMENT}

5 The authors would like to acknowledge the feedback on the article from Dr Ken Whyte of the Auckland 6 District Health Board. 


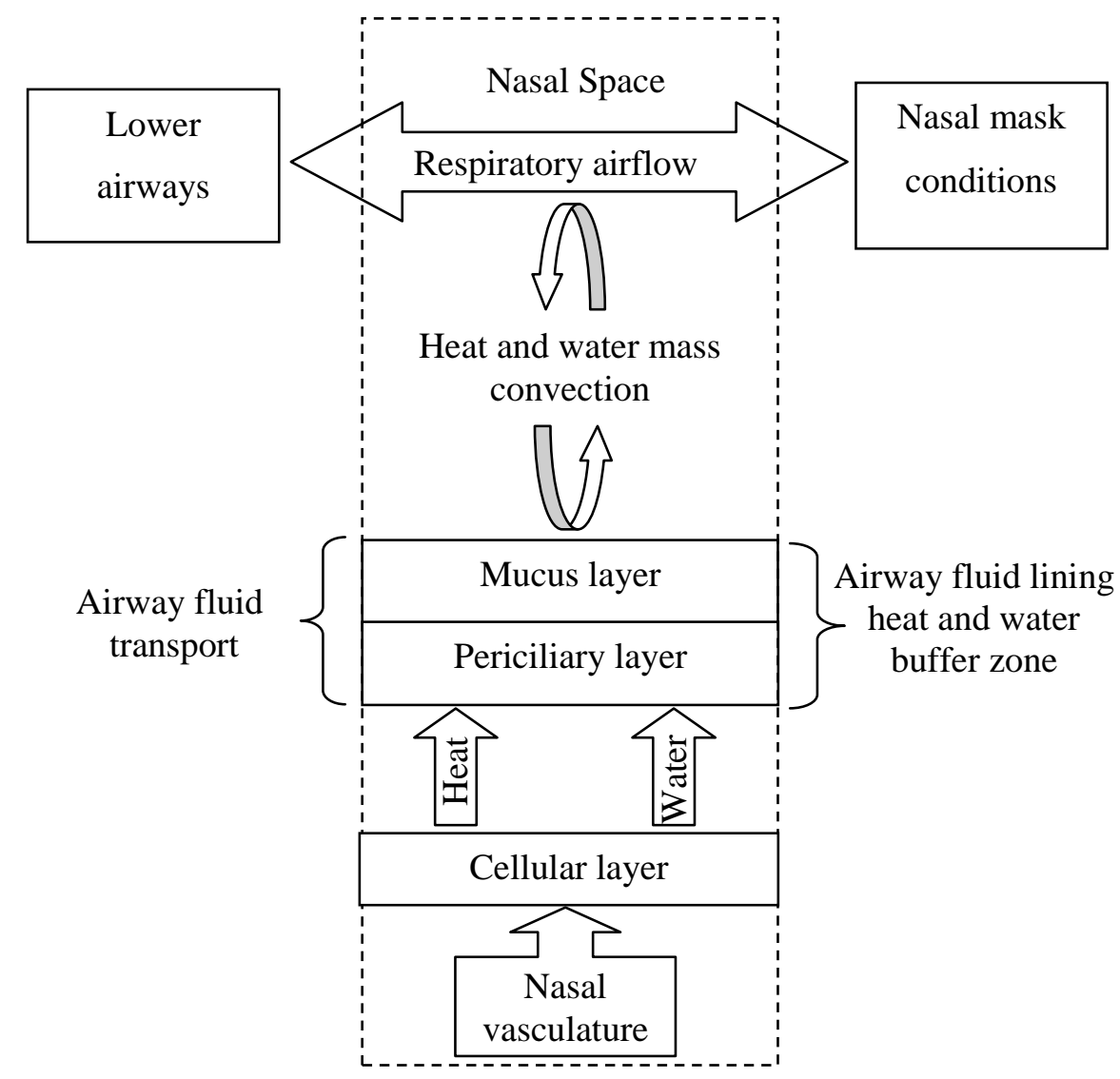

2

Figure 1. Schematic representation of human respiratory air-conditioning elements. 


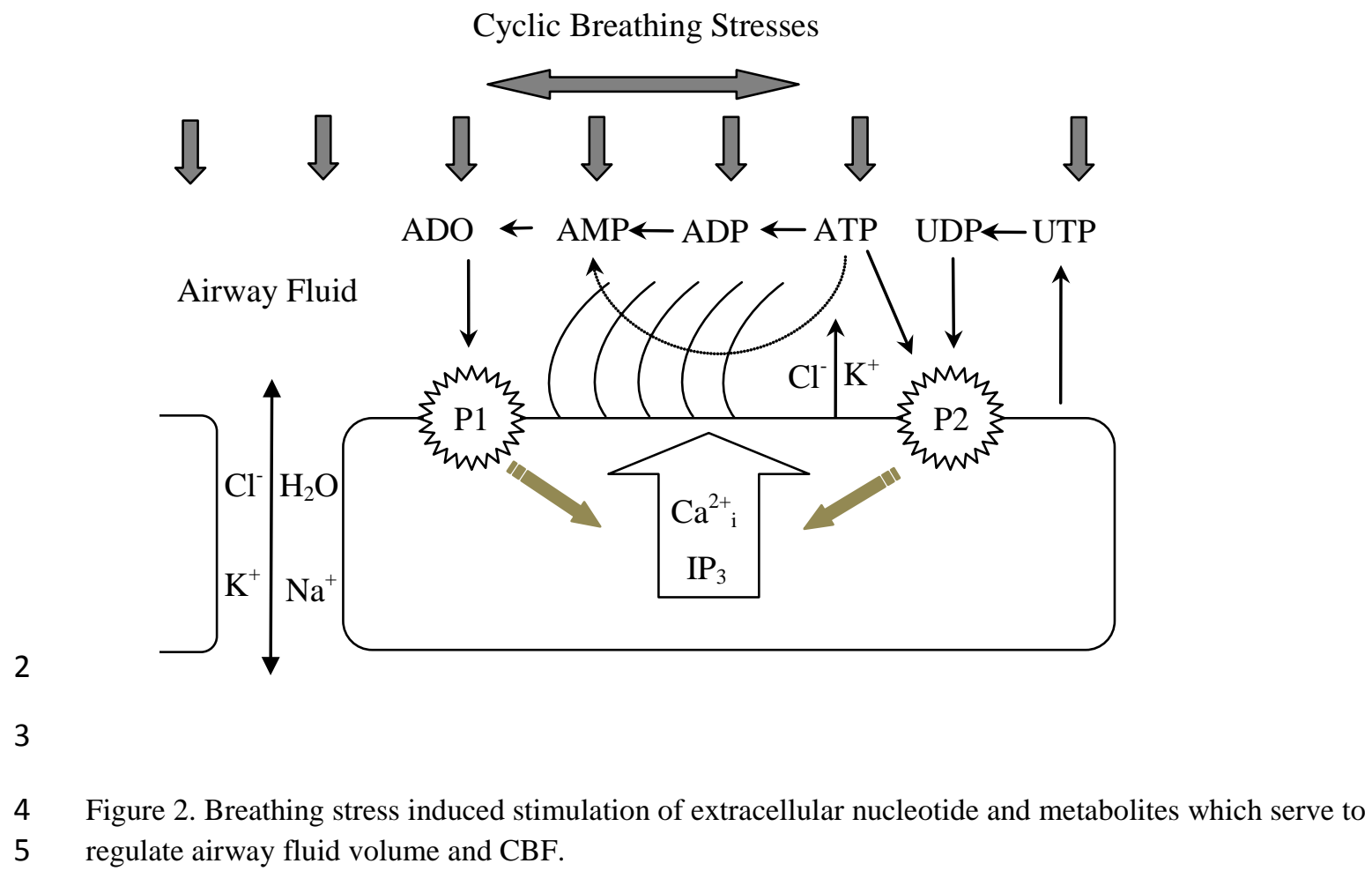




\section{REFERENCES}

[1] Martins de Araujo MT, Vieira SB, Vasquez EC, Fleury B. Heated humidification or face mask to prevent upper airway dryness during continuous positive airway pressure therapy. Chest. 2000;117:142-7.

[2] Wiest GH, Lehnert G, Brûck WM, Meyer M, Hahn EG, Ficker JH. A heated humidifier reduces upper airway dryness during continuous positive airway pressure therapy. Respir Med. 1999;93(1):21-6.

[3] Wiest GH, Fuchs FS, Brueckl WM, et al. In vivo efficacy of heated and non-heated humidifiers during nasal continuous positive airway pressure (nCPAP)-therapy for obstructive sleep apnoea. Respir Med. 2000;94(4):364-8.

[4] Malik NW, Kenyon GS. Changes in the nasal airway mucosa and in nasal symptoms following continuous positive airway pressure ( $\mathrm{n}$ CPAP) for obstructive sleep apnoea. Australian Journal of Oto-Laryngology. 2004;7(1):17-20.

[5] Mador MJ, Matthew K, Adnan P, Dawn P, Mark B. Effect of heated humidification on compliance and quality of life in patients with sleep apnea using nasal continuous positive airway pressure. Chest. 2005;128(4):2151-8.

[6] Constantinidis J, Knobber D, Steinhart H, Kuhn J, Iro H. Fine-structural investigations of the effect of nCPAP-mask application on the nasal mucosa. Acta Otolaryngol (Stockh). 2000;120(3):432-7.

[7] Worsnop CJ, Miseski S, Rochford PD. The routine use of humidification with nasal continuous positive airway pressure. Journal [serial on the Internet]. 2009 Date; 9999(999A): Available from: http://dx.doi.org/10.1111/j.1445-5994.2009.01969.x.

[8] Rakotonanahary D, Pelletier-Fleury N, Gagnadoux F, Fleury B. Predictive factors for the need for additional humidification during nasal continuous positive airway pressure therapy. Chest. 2001;119(2):460-5.

[9] Hollandt JH, Mahlerwein M. Nasal breathing and continuous positive airway presure (CPAP) in patients with obstructive sleep apnea (OSA). Sleep and Breathing. 2003;7(2):87-93. [10] Fischer Y, Keck T, Leiacker R, Rozsasi A, Rettinger G, Gruen PM. Effects of nasal mask leak and heated humidification on nasal mucosa in the therapy with nasal continuous positive airway pressure (nCPAP). Sleep Breath. 2008;12:353-7.

[11] Devouassoux G, Lévy P, Rossini E, et al. Sleep apnea is associated with bronchial inflammation and continuous positive airway pressure-induced airway hyperresponsiveness. J Allergy Clin Immunol. 2007;119(3):597-603.

[12] Arfoosh R, Rowley J. Continuous positive airway pressure for obstructive sleep apnea: an update. Journal of Respiratory Diseases. 2008;29(9):365-73.

[13] Massie CA, Hart RW, Peralez K, Richards GN. Effects of humidification on nasal symptoms and compliance in sleep apnea patients using continuous positive airway pressure. Chest. 1999;116:403-8.

[14] Richards GN, Cistulli PA, Ungar RG, Berthon-Jones M, Sullivan CE. Mouth leak with nasal continuous positive airway pressure increases nasal airway resistance. Am J Respir Crit Care Med. 1996;154:182-6.

[15] Neill AM, Wai HS, Bannan STP, Beasley CR, Weatherall M, Campbell AJ. Humidified nasal continuous positive airway pressure in obstructive sleep apnea. Eur Respir J. 2003;22:258-62.

[16] Lindemann J, Sannwald D, Wiesmiller K. Age-related changes in intranasal air conditioning in the elderly. Laryngoscope. 2008;118(8):1472-5.

[17] Holland AE, Denehy L, Buchan CA, Wilson JW. Efficacy of a heated passover humidifier during noninvasive ventilation: a bench study. Respir Care. 2007;52(1):38-44. 
[18] Williams RB, Rankin N, Smith T, Galler D, Seakins P. Relationship Between the Humidity and Temperature of Inspired Gas and the Function of the Airway Mucosa. Crit Care Med. 1996;24(11):1920-9.

[19] Williams RB. The Effects of Excessive Humidity. Respir Care Clin N Am. 1998;4(2):21528.

[20] Sottiaux TM. Consequences of Under-and Over-Humidification. Respir Care Clin N Am. 2006;12(2):233-52.

[21] Solomita M, Samldone GC. Humidification and Noninvasive Ventilation. Respir Care. 2007 Jan 2007;52(1):24-5.

[22] Wolf M, Naftali S, Schroter RC, Elad D. Air-conditioning characteristics of the human nose. J Laryngol Otol. 2004;118(2):87-92.

[23] Walker JEC, Wells RE. Heat and water exchange in the respiratory tract. Am J Med. 1961;30(2):259-67.

[24] Tarran R, Trout L, Donaldson SH, Boucher RC. Soluble Mediators, Not Cilia, Determine Airway Surface Liquid Volume in Normal and Cystic Fibrosis Superficial Airway Epithelia. J Gen Physiol. 2006 April 24, 2006;127(5):591-604.

[25] Trout L, King M, Feng W, Inglis SK, Ballard ST. Inhibition of airway liquid secretion and its effect on the physical properties of airway mucus. Am J Physiol Lung Cell Mol Physiol. 1998 February 1, 1998;274(2):L258-63.

[26] Button B, Boucher RC. Role of mechanical stress in regulating airway surface hydration and mucus clearance rates. Respir Physiol Neurobiol. 2008;163(1-3):189-201.

[27] Winther B, Gwaltney JR. Microbiology of Sinusitis. In: Kennedy DW, Bolger WE, Zinreich SJ, editors. Diseases of the Sinuses - Diagnosis and Management Ontario: B.C. Decker Inc.; 2001. p. 77-84.

[28] Bossi R, Piatti G, Roma E, Ambrosetti U. Effects of long-term nasal continuous positive airway pressure therapy on morphology, function, and mucociliary clearance of nasal epithelium in patients with obstructive sleep apnea syndrome. Laryngoscope. 2004;114(8):1431-4.

[29] Silberberg A. Rheology of mucus, mucociliary interaction, and ciliary activity. Cell Motil Cytoskeleton. 1982;2(S1):25-8.

[30] Smith DJ, Gaffney EA, Blake JR. Modelling mucociliary clearance. Respir Physiol Neurobiol. 2008;163(1-3):178-88.

[31] Brand RW, Isselhard DE. Anatomy of orofacial structures. 7th ed. St Louis: Mosby; 2003.

[32] Guyton AC, Hall JE. Textbook of medical physiology. 10th ed. Schmitt W, editor. Philadelphia: W.B. Saunders Company; 2000.

[33] Stierna PLE. Physiology, Mucociliary Clearance and Neutral Control. In: Kennedy DW, Bolger WE, Zinreich SJ, editors. Diseases of the Sinuses - Diagnosis and Management. Ontario: B.C. Decker Inc.; 2001. p. 35-45.

[34] Widdicombe JH. Regulation of the depth and composition of airway surface liquid. J Anat. 2002;201(4):313-8.

[35] Wiesmiller K, Keck T, Leiacker R, Lindemann J. Simultaneous in vivo measurements of intranasal air and mucosal temperature. Eur Arch Otorhinolaryngol. 2007 Jun;264(6):615-9.

[36] Cole P. The four components of the nasal valve. Am J Rhinol. 2003;17(2):107-10.

[37] Lindemann J, Leiacker R, Rettinger G, Keck T. Nasal mucosal temperature during respiration. Clin Otolaryngol. 2002;27(3):135-9.

[38] Naclerio RM, Pinto JM, Assanasen P, Baroody FM. Observations on the ability of the nose to warm and humidify inspired air. Rhinology. 2007;47:102-11.

[39] Cauna N, Hinderer KH, Wentges RT. Sensory receptor organs of the human nasal respiratory mucosa. Am J Anat. 1969;124(2):187-209. 
1 [40] Cauna N. Blood and nerve supply of the nasal lining. In: Proctor DF, Andersen I, editors.

2 The nose: upper airway physiology and the atmospheric environment. Amsterdam: Elsevier

3 Biomedical Press; 1982. p. 45-66.

4 [41] Raphael GD, Meredith SD, Baraniuk JN, Kaliner MA. Nasal Reflexes. Am J Rhinol. 5 1988;2(3):109-16.

6 [42] Eccles R. Neurological and pharmacological considerations. In: Proctor DF, Andersen I, 7 editors. The nose: upper airway physiology and the atmospheric environment. Amsterdam:

8 Elsevier Biomedical Press; 1982. p. 191-214.

9 [43] Kurita N, Hasegawa M, Ohki M, Watanabe I. Nasal resistance and nasal blood flow in

[44] Bove PF, van der Vliet A. Nitric oxide and reactive nitrogen species in airway epithelial signaling and inflammation. Free Radic Biol Med. 2006;41(4):515-27.

[45] Laursen BE, Stankevicius E, Pilegaard H, Mulvany M, Simonsen U. Potential protective properties of a stable, slow-releasing nitric oxide donor, GEA 3175, in the lung. Cardiovasc Drug Rev. 2006;24(3-4):247-60.

[46] Chambers DC, Carpenter DA, Ayres JG. Exchange dynamics of nitric oxide in the human nose. J Appl Physiol. 2001 November 1, 2001;91(5):1924-30.

[47] Serrano C, Valero A, Picado C. Nasal nitric oxide. Archives of Bronconeumology. 2004;40(5):222-30.

[48] Corbelli R, Hammer J. Measurement of nasal nitric oxide. Paediatr Respir Rev. 2007;8(3):269-72.

[49] Nakano $\mathrm{H}$, Ide $\mathrm{H}$, Ogasa $\mathrm{T}$, et al. Ambient oxygen regulates epithelial metabolism and nitric oxide production in the human nose. J Appl Physiol. 2002;93(1):189-94.

[50] Giraud GD, Nejadnik B, Kimberly B, Holden WE. Physical characteristics and gas composition of nasal air affect nasal nitric oxide release. Respir Physiol. 1998;114(3):285-96.

[51] Tasman AJ, Bogatzki B, Heppt W, Hauser-Kronberger C, Fischer A. Nitric Oxide Synthase in the Innervation of the Human Nasal Mucosa: Correlation With Neuropeptides and Tyrosine Hydroxylase. Laryngoscope. 1998;108(1):128-33.

[52] Klimek L. Potential of levocetirizine in the relief of nasal congestion. Int J Clin Pract. 2005;59(6):721-9.

[53] Howarth P. Clinical nasal decongestant activity with oral antihistamines. Clin Exp Allergy Rev. 2002;2(3):101-6.

[54] Malm L. Responses of resistance and capacitance vessels in feline nasal mucosa to vasoactive agents. Acta Otolaryngol (Stockh). 1974;78(1-6):90-7.

[55] Churchill SE, Shackelford LL, Georgi JN, Black MT. Morphological variation and airflow dynamics in the human nose. Am J Hum Biol. 2004;16(6):625-38.

[56] Cole P, Roithmann R. The nasal valve and current technology. Am J Rhinol. 1996;10(1):23-31.

[57] Widdicombe J. Why are the airways so vascular? Thorax. 1993;48:290-5.

[58] Hanif J, Jawad SSM, Eccles R. The nasal cycle in health and disease. Clin Otolaryngol. 2000;25(6):461-7.

[59] Davis SS, Eccles R. Nasal congestion: mechanisms, measurement and medications. Core information for the clinician. Clin Otolaryngol. 2004;29(6):659-66.

[60] Hasegawa M, Ohki M, Kurita N. Effects of posture on the nasal cycle. Am J Rhinol. 1990;4(3):101-4.

[61] Wilde AD, Jones AS. The nasal response to axillary pressure. Clin Otolaryngol. 1996;21(5):442-4.

[62] Shannahoff-khalsa DS, Yates FE. Ultradian Sleep Rhythms of Lateral EEG, Autonomic, and Cardiovascular Activity Are Coupled in Humans. Int J Neurosci. 2000;101(1-4):21-43.

[63] Lindemann J, Leiacker R, Rettinger G, Keck T. The relationship between water vapour saturation of inhaled air and nasal patency. Eur Respir J. 2003 February 1, 2003;21(2):313-6. 
[64] Atanasov Al, Dimov PD, Dimitrov BD. Time periods in the nasal cycle during night sleep. Biol Rhythm Res. [Article]. 2003 Oct;34(4):355-66.

[65] Druce HM. Measurement of nasal mucosal blood flow. J Allergy Clin Immunol. 1988;81(3):505-8.

[66] Qian W, Sabo R, Ohm M, Haight JSJ, Fenton RS. Nasal nitric oxide and the nasal cycle. Laryngoscope. 2001;111:1603-7.

[67] Azzaroni A, Parmeggiani PL. Synchronized sleep duration is related to tonic vasoconstriction of thermoregulatory exchangers. J Sleep Res. 1995;4(1):41-7.

[68] Shannahoff-Khalsa D. The Ultradian Rhythm of Alternating Cerebral Hemispheric Activity. Int J Neurosci. 1993;70(3-4):285-98.

[69] Elad D, Wolf M, Keck T. Air-conditioning in the human nasal cavity. Respir Physiol Neurobiol. 2008;163(1-3):121-7.

[70] Widdicombe J. Microvascular anatomy of the nose. Allergy. 1997;52(s40):7-11.

[71] Holden WE, Sippel JM, Nelson B, Giraud GD. Greater nasal nitric oxide output during inhalation: effects on air temperature and water content. Respir Physiol Neurobiol. 2009;165(1):22-7.

[72] Djupesland PG, Chatkin JM, Qian W, Haight JSJ. Nitric oxide in the nasal airway: a new dimension in otorhinolaryngology. Am J Otolaryngol. 2001;22(1):19-32.

[73] Jiang C, Finkbeiner WE, Widdicombe JH, Miller SS. Fluid transport across cultures of human tracheal glands is altered in cystic fibrosis. J Physiol. 1997;501(3):637-47.

[74] Wine JJ. Parasympathetic Control of Airway Submucosal Glands: Central Reflexes and the Airway Intrinsic Nervous System. Auton Neurosci Basic Clin. 2007;1(133):35-54.

[75] Widdicombe JG, Wells UM. Airway Secretions. In: Proctor DF, Andersen I, editors. The Nose: Upper Airway Physiology and the Atmospheric Environment. Amsterdam: Elsevier Biomedical Press; 1982. p. 215-44.

[76] Tarran R, Button B, Boucher RC. Regulaton of Normal and Cystic Fibrosis Airway Surface Liquid Volume by Phasic Shear Stress. Annu Rev Physiol. 2006;68:543-61.

[77] Théâtre E, Bours V, Oury C. A P2X Ion Channel-Triggered NF-[kappa]B Pathway Enhances TNF-[alpha]-Induced IL-8 Expression in Airway Epithelial Cells. Am J Respir Cell Mol Biol. 2009;41(6):705-13.

[78] Hayashi T, Kawakami M, Sasaki S, et al. ATP regulation of ciliary beat frequency in rat tracheal and distal airway epithelium. Exp Physiol. 2005;90(4):535-44.

[79] Satsuki A, Yuichi M. Nasal mucociliary clearance of chronic sinusitis in relation to rheological properties of nasal mucus. Ann Otol Rhinol Laryngol. 1998;107(1):47-51.

[80] Gheber L, Korngreen A, Priel Z. Effect of viscosity on metachrony in mucus propelling cilia. Cell Motil Cytoskeleton. 1998;39:9-20.

[81] Horváth G, Sorscher EJ. Luminal fluid tonicity regulates airway ciliary beating by altering membrane stretch and intracellular calcium. Cell Motil Cytoskeleton. 2008;65(6):46975.

[82] Jain B, Rubinstein I, Robbins RA, Leise KL, Sisson JH. Modulation of airway epithelial cell ciliary beat frequency by nitric oxide. Biochem Biophys Res Commun. 1993;191(1):83-8.

[83] Kim JW, Min YG, Rhee CS, et al. Regulation of mucociliary motility by nitric oxide and expression of nitric oxide synthase in the human sinus epithelial cells. Laryngoscope. 2001;111(2):246-50.

[84] Choi J, Joo N, Krouse M, et al. Synergistic airway gland mucus secretion in response to vasoactive intestinal peptide and carbachol is lost in cystic fibrosis. J Clin Invest.

2007;117(10):3118-27.

48 [85] Davis CW, Lazarowski E. Coupling of airway ciliary activity and mucin secretion to 49 mechanical stresses by purinergic signaling. Respir Physiol Neurobiol. 2008;163(1-3):208-13.

50 [86] Knight GE, Bodin P, De Groat WC, Burnstock G. ATP is released from guinea pig ureter epithelium on distension. Am J Physiol Renal Physiol. 2002 February 1, 2002;282(2):F281-8. 
1 [87] Homolya L, Steinberg TH, Boucher RC. Cell to cell communication in response to 2 mechanical stress via bilaterial release of ATP and UTP in polarized epithelia. J Cell Biol. 3 2000;150(6):1349-59.

4 [88] Lazarowski ER, Tarran R, Grubb BR, van Heusden CA, Okada SF, Boucher RC. Nucleotide 5 release provides a mechanism for airway surface liquid homeostasis. J Biol Chem. 2004 August 6 27, 2004;279(35):36855-64.

7 [89] Tarran R, Button B, Picher M, et al. Normal and Cystic Fibrosis Airway Surface Liquid 8 Homeostasis. J Biol Chem. 2005 October 21, 2005;280(42):35751-9.

9 [90] Basser PJ, McMahon TA, Griffith P. The mechanism of mucus clearance in cough. J 10 Biomech Eng. 1989 Nov;111(4):288-97.

11 [91] Button B, Picher M, Boucher RC. Differential effects of cyclic and constant stress on 2007;580(2):577-92.

[92] Ahmed B. Comparison of nasal prong pressure and thermistor measurements for detecting respiratory events during sleep. Respiration. 2004;71(4):385-90.

[93] Elad D, Naftali S, Rosenfeld M, Wolf M. Physical stresses at the air-wall interface of the human nasal cavity during breathing. J Appl Physiol. 2006 March 1, 2006;100(3):1003-10.

[94] Lieb T, Frei CW, Frohock JI, Bookman RJ, Salathe M. Prolonged increase in ciliary beat frequency after short-term purinergic stimulation in human airway epithelial cells. J Physiol. 2002;538(2):633-46.

[95] Zhang L, Sanderson MJ. Oscillations in ciliary beat frequency and intracellular calcium concentration in rabbit tracheal epithelial cells induced by ATP. J Physiol. 2003;546(3):733-49.

[96] Bucheimer RE, Linden J. Purinergic regulation of epithelial transport. J Physiol. 2004;555(2):311-21.

[97] Sanderson MJ, Dirksen ER. Mechanosensitivity of cultured ciliated cells from the mammalian tespiratory tract: implications for the regulation of mucociliary transport. Proc Natl Acad Sci U S A. 1986;83:7302-6.

[98] Leuba D, De Ribaupierre Y, Kucera P. Ion transport, ciliary activity, and mechanosensitivity of sinusal mucosa: an in vitro study. American Journal of Physiology - Lung and Cellular Moloecular Physiology. 1996 September 1, 1996;271(3):L349-58.

[99] Kilgour E, Rankin N, Ryan S, Pack R. Mucociliary function deteriorates in the clinical range of inspired air temperature and humidity. Intensive Care Med. 2004;30:1491-4.

[100] Morse DM, Smullen JL, Davis CW. Differential effects of UTP, ATP, and adenosine on ciliary activity of human nasal epithelial cells. Am J Physiol Cell Physiol. 2001;280(6):C1485-97. [101] Evans JH, Sanderson MJ. Intracellular calcium oscillations regulate ciliary beat frequency of airway epithelial cells. Cell Calcium. 1999;26(3-4):103-10.

[102] Burnstock G. Purinergic signalling. Br J Pharmacol. 2006;147(S1):S172-81.

[103] Clarke LL, Chinet T, Boucher RC. Extracellular ATP stimulates K+ secretion across cultured human airway epithelium. American Journal of Physiology - Lung and Cellular Moloecular Physiology. 1997 June 1, 1997;272(6):L1084-91.

[104] Mall M, Wissner A, Gonska T, Calenborn D. Inhibition of amiloride-sensitive epithelial $\mathrm{Na}+$ absorption by extracellular nucleotides in human normal and cystic fibrosis airways. Am J Respir Cell Mol Biol. 2000;23(6):755-61.

[105] Stutts MJ, Chinet TC, Mason SJ, Fullton JM, Clarke LL, Boucher RC. Regulation of $\mathrm{Cl}$ (Minus) Channels in Normal and Cystic Fibrosis Airway Epithelial Cells by Extracellular ATP. Proc Natl Acad Sci U S A. 1992;89(5):1621-5.

[106] Zsembery Ãk, Fortenberry JA, Liang L, et al. Extracellular Zinc and ATP Restore Chloride Secretion across Cystic Fibrosis Airway Epithelia by Triggering Calcium Entry. J Biol Chem. 2004 March 12, 2004;279(11):10720-9. 
1 [107] Mason SJ, Paradiso AM, Boucher RC. Regulation of transepithelial ion transport and

2 intracellular calcium by extracellular ATP in human normal and cystic fibrosis airway

3 epithelium. Br J Pharmacol. 1991;103(3):1649-56.

4 [108] Korngreen A, Ma W, Priel Z, Silberberg SD. Extracellular ATP directly gates a cation-

5 selective channel in rabbit airway ciliated epithelial cells. J Physiol. 1998;508(3):703-20.

6 [109] Franklin HE, Patricio S. Na-K-Cl cotransport in chloride-transporting epithelia. Ann N Y

7 Acad Sci. 1985;456:187-97.

8 [110] Crews A, Taylor AE, Ballard ST. Liquid transport properties of porcine tracheal

9 epithelium. J Appl Physiol. 2001 August 1, 2001;91(2):797-802.

10 [111] Farinas J, Kneen M, Moore M, Verkman AS. Plasma membrane water permeability of 11 cultured cells and epithelia measured by light microscopy with spatial filtering. J Gen Physiol. 12 1997;110:283-96.

13 [112] Matsui H, Davis CW, Tarran R, Boucher RC. Osmotic water permeabilities of cultured, well-differentiated normal and cystic fibrosis epithelia. J Clin Invest. 2000;105(10):1419-27. [113] Tarran R, Grubb BR, Gatzy JT, Davis CW. The Relative Roles of Passive Surface Forces and Active Ion Transport in the Modulation of Airway Surface Laquid Volume and Composition. J Gen Physiol. 2001;118(2):223-36.

[114] Knowles RM, Robinson JM, Wood RE, Pue CA, Mentz WM, Wager GC. Ion composition of airway surface liquid of patients with cystic fibrosis as compared with normal and diseasecontrol subjects. J Clin Invest. 1997;100(10):2588-95.

[115] Boucher RC. Molecular insights into the physiology of the 'thin film' of airway surface liquid. J Physiol. 1999;516(3):631-8.

[116] Hanna LM. Modelling of heat and water vapor transport in the human respiratory tract (air-conditioning) [Ph.D.]. United States -- Pennsylvania: University of Pennsylvania; 1983. [117] Doorly DJ, Taylor DJ, Schroter RC. Mechanics of airflow in the human nasal airways. Respiratory Physiology and Neurobiology. 2008;163(1-3):100-10.

[118] Doorly D, Taylor DJ, Franke P, Schroter RC. Experimental investigation of nasal airflow. Proc Inst Mech Eng [H]. 2008;222(H4):439-53.

[119] Croce $C$, Fodil R, Durand $M$, et al. In vitro experiments and numerical simulations of airflow in realistic nasal airway geometry. Ann Biomed Eng. 2006 2006;34(6):997-1007.

[120] Hanna LM, Scherer PW. Regional control of local airway heat and water vapor losses. J Appl Physiol. 1986 August 1, 1986;61(2):624-32.

[121] Keck T, Leiacker R, Riechelmann H, Rettinger $G$. Temperature profile in the nasal cavity. Laryngoscope. 2000;110(4):651-4.

[122] Naftali S, Rosenfeld, M., Wolf, M., Elad, D. The air-conditioning capacity of the human nose. Ann Biomed Eng. 2005 2005;33(4):545-53.

[123] Naftali S, Schroter, R.C., Shiner, R.J., Elad, D. Transport phenomena in the human nasal cavity: a computational model. Ann Biomed Eng. 1998 1998;26:831-9.

[124] Lindemann J, Keck T, Wiesmiller K, et al. A Numerical Simulation of Intranasal Air Temperature During Inspiration. Laryngoscope. 2004;114(6):1037-41.

[125] Pless D, Keck T, Wiesmiller K, et al. Numerical simulation of air temperature and airflow patterns in the human nose during expiration. Clin Otolaryngol. 2004;29(6):642-7.

[126] Lindemann J, Keck T, Wiesmiller K, et al. Nasal air temperature and airflow during respiration in numerical simulation based on multislice computed tomography scan. Am J Rhinol. 2006;20(2):219-23.

[127] Bogdanffy MS, Sarangapani R. Physiologically-based kinetic modeling of vapours toxic to the respiratory tract. Toxicol Lett. 2003;138(1-2):103-17.

[128] Bailie N, Hanna B, Watterson J, Gallagher G. A model of airflow in the nasal cavities: Implications for nasal air conditioning and epistaxis. American Journal of Rhinology and Allergy. 2009;23(3):244-9. 
[129] Hood C, Schroter R, Doorly D, Blenke E, Tolley N. Computational modeling of flow and gas exchange in models of the human maxillary sinus. J Appl Physiol. 2009;107(4):1195-203. [130] Fodil R, Brugel-Ribere L, Croce C, et al. Inspiratory Flow in the Nose: a Model Coupling Flow and Vasoerectile Tissue Distensibility. J Appl Physiol. 2005;98:288-95.

[131] Daviskas E, Gonda I, Anderson SD. Local airway heat and water vapour losses. Respir Physiol. 1991;84(1):115-32.

[132] Daviskas E, Gonda I, Anderson SD. Mathematical modeling of heat and water transport in human respiratory tract. J Appl Physiol. 1990 July 1, 1990;69(1):362-72.

[133] Tawhai MH, Hunter, P.J. Modeling Water Vapor and Heat Transfer in the normal and the Intubated Airways. Ann Biomed Eng. 2003 2003;32(4):609-22.

[134] Clarke RW, Cook JA, Jones AS. The effect of nasal mucosal vasoconstriction on nasal airflow sensation. Clin Otolaryngol. 1995;20(1):72-3.

[135] Sahin-Yilmaz A, Baroody FM, DeTineo M, et al. Effect of changing airway pressure on the ability of the human nose to warm and humidify air. Ann Otol Rhinol Laryngol. 2008;117(7):501-7.

[136] Head CA. Nitric oxide and the lung: an overview. Artif Organs. 1997;21(1):5-9.

[137] Matera MG. Nitric oxide and airways. Pulm Pharmacol Ther. 1998;11:341-8.

[138] Assanasen P, Baroody FM, Naureckas E, Solway J, Naclerio RM. Supine position decreases the ability of the nose to warm and humidify air. J Appl Physiol. 2001 December 1, 2001;91(6):2459-65.

[139] Lung MA, Phipps RJ, Wang JCC, Widdicombe JG. Control of Nasal Vasculature and Airflow Resistance in the Dog. J Physiol. 1984;349:535-51.

[140] Rozsasi A, Leiacker R, Keck T. Nasal conditioning in perennial allergic rhinitis after nasal allergen challenge. Clin Exp Allergy. 2004;34(7):1099-104.

[141] Safwan SJ, Timothy LS, Laura T, et al. Autonomic nervous system evaluation of patients with vasomotor rhinitis. Laryngoscope. 2000;110(11):1828-31.

[142] Terrye M. Recognizing And Treating Non-Infectious Rhinitis. J Am Acad Nurse Pract. 2003;15(9):398-409.

[143] Bachert C. Persistent rhinitis - allergic or nonallergic? Allergy. 2004;59(s76):11-5.

[144] Ciprandi G. Treatment of nonallergic perennial rhinitis. Allergy. 2004;59(s76):16-23.

[145] Berg S, Wollmer P, Andersson M, Persson CGA, Greiff L. Effects of experimental changes in nasal airway pressure on mucosal output of plasma. Clin Physiol Funct Imaging. 2003;23:155-8.

[146] Burnett A. Erectile dysfunction: science and medicine. Annu Rev Sex Res. 2006;17:10115.

[147] Yuan Y, Hoang A, Romero C, Lin H, Dai Y, Wang R. Vacuum Therapy in Erectile Dysfunction - Science and Clinical Evidence. Journal [serial on the Internet]. 2010 Date; 4(22): Available from: http://www.medscape.com/viewarticle/725873.

[148] O'Hearn DJ, Giraud GD, Sippel JM, Edwards C, Chan B, Holden W. Exhaled nasal nitric oxide output is reduced in humans at night during sleep period. Respir Physiol Neurobiol. 2007;156:94-101.

[149] Menzel L, Hess A, Bloch W, et al. Temporal nitric oxide dynamics in the paranasal sinuses during humming. J Appl Physiol. 2005 June 1, 2005;98(6):2064-71.

[150] Maniscalco M, Weitzberg E, Sundberg J, Sofia M, Lundberg JO. Assessment of nasal and sinus nitric oxide output using single-breath humming exhalations. Eur Respir J. 2003 August 1, 2003;22(2):323-9.

[151] Shusterman DJ, Jansen K, Weaver EM, Koenig JQ. Documentation of the nasal nitric oxide response to humming: methods evaluation. Eur J Clin Invest. 2007;37(9):746-52. [152] Andersson JA, Cervin A, Lindberg S, Uddman R, Cardell LO. A decrease in maxillary sinus pressure, as seen in upper airway allergy or infection, results in an increase in upper airway nitric oxide levels. Acta Otolaryngol (Stockh). 2002;122(5):520-3. 
1 [153] Relova AJ, Roomans GM. Effect of luminal osmolarity on ion content of connective tissue in rat trachea after epithelial damage. Eur Respir J. 2001 November 1, 2001;18(5):810-6. [154] Lee HP, Poh HJ, Chong FH, Wang DY. Changes of airflow pattern in inferior turbinate hypertrophy: A computational fluid dynamics model. American Journal of Rhinology and Allergy. 2009;23(2):153-8.

[155] Mwimbi XKMS, Muimo R, Green MW, Mehta A. Making human nasal cilia beat in the cold: a real time assay for cell signalling. Cell Signal. 2003;15(4):395-402.

[156] Clary-Meinesz CF, Cosson J, Huitorel P, Blaive B. Temperature effect on the ciliary beat frequency of human nasal and tracheal ciliated cells. Biol Cell. 1992;76(3):335-8.

10 [157] Cruz AA, Naclerio RM, Proud D, Togias A. Epithelial shedding is associated with nasal reactions to cold, dry air. J Allergy Clin Immunol. 2006;117(6):1351-8.

[158] Chu YH, Wu CC, Wu CH, Wang HW. Low temperature results in decreased tension in decellularized human nasal mucosa. American journal of Rhinology and Allergy. 2009;23(2):162-6.

[159] Kirkness JP, Eastwood PR, Szollosi I, et al. Effect of surface tension of mucosal lining liquid on upper airway mechanics in anesthetized humans. J Appl Physiol. 2003;95(1):357-63. [160] Verma M, Seto-Poon M, R. Wheatley JR, T.C. A, Kirkness JP. Influence of breathing route on upper airway lining liquid surface tension in humans. J Physiol. 2006;574(3):859-66. [161] Lai SK, Wang YY, Wirtz D, Hanes J. Micro and macrorheology of mucus. Adv Drug Delivery Rev. 2009;61:86-100.

[162] Quraishi MS, Jones NS, Mason J. The rheology of nasal mucus: a review. Clin Otolaryngol. 1998;23(5):403-13.

[163] Lindemann J, Tsakiropoulou E, Vital V, et al. Influence of the turbinate volumes as measured by magnetic resonance imaging on nasal air conditioning. American Journal of Rhinology and Allergy. 2009;23(3):250-4.

[164] Monteseirin J, Camacho MJ, Bonilla I, Sánchez-Hernández C, Hernández M, Conde J. Honeymoon rhinitis. Allergy. 2001;56(4):353-4.

[165] Shah A, M. S. Postcoital asthma and rhinitis. Chest. 1991;100:1039-41.

[166] Bartley J. Nasal congestion and hyperventilation syndrome. Am J Rhinol. 2005;19(6):607-11.

[167] Jella SA, Shannahoff-khalsa DS. The effects of unilateral forced nostril breathing on cognitive performance. Int J Neurosci. 1993;73(1-2):61-8.

[168] Shannahoff-khalsa DS, Boyle MR, Buebel ME. The Effects of Unilateral Forced Nostril Breathing on Cognition. Int J Neurosci. 1991;57(3-4):239-49. 